Pak. j. sci. ind. res. Ser. A: phys. sci. 2018 61A(2) 100-105

\title{
Effect of Dyeing Temperature on the Shrinkage and Fastness Properties of Polyester/Acrylic Fabric
}

\author{
Musaddaq Azeem ${ }^{\mathrm{a}}$, Ahmed Fraz ${ }^{* \mathrm{~b}}$ and Asif Javed \\ ${ }^{a}$ Faculty of Textile Engineering, Technical University of Liberec, Czech Republic

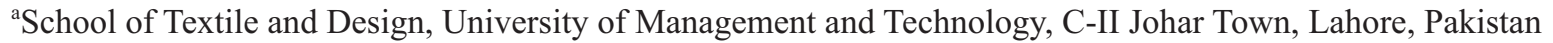

(received January 15, 2018; revised March 3, 2018; accepted March 5, 2018)

\begin{abstract}
The dyeing rate of acrylic and polyester tends to start at $100{ }^{\circ} \mathrm{C}$, and carriers are also used frequently to enhance the rate. Herein, the acrylic, polyester and polyester/acrylic blend of woven fabrics were dyed at different temperatures and by keeping the additional parameters constant. The ultimate effect of dyes-uptake observed favourable regarding colour fastness properties. With the increase in temperature, the variation in shrinkage was highly predicted. A significant effect was analysed by increasing the temperature of the dye through the fibre. The colour fastness of the dyed samples was also evaluated.
\end{abstract}

Keywords: acrylic, polyester, polyester/acrylic blended fabric, shrinkage, fastness properties

\section{Introduction}

The demand of high quality apparels and upholstery has been increased with the brisk improvement of people's living. Synthetic fabrics are making progress worldwide especially polyester, acrylic and blends of both are contributing as one of the largest shares of the textiles in different formats. Acrylic is lightweight, soft, and warm, with a wool-like feel and can be used to mimic other fibres, such as cotton, when spun on short staple equipment. The fabrics made of this yarn are quick drying and resistant to sunlight, fading, mildew and insects. Polyester is strong and durable with good resistance to abrasion. It stands up well to sunlight, mildew, and insects. Blends of polyester and acrylic fibre are important in woven upholstery and finishing; easy care suiting, outwear and dress-wear. Acrylics have moderate dimensional stability (Siddique, 1999).

Dyeing, the process of imparting colour to a textile material, involves many processes such as substantively, adsorption, absorption, exhaustion and fixation of dye molecule on the textile material. The dyeability of a fibre is a measure of the ability to fix the dye molecules within the fibre. It involves a process of adsorption, exhaustion and fixation of dye molecules (Ujhelyiova et al., 2007). The knowledge of dyebath and specifications of the textile material is necessary for a successful dyeing. For instance, before dyeing,

*Author for correspondence;

E-mail: ahmadfraz165@gmail.com the textile material must be free from impurities to get a uniform application of dye (Siddiqui and Needles, 1982). Therefore, an appropriate process of scouring, desizing and bleaching is applied to ensure this condition.

Dyeing of polyester/acrylic blended woven fabrics is done by two different types of dyestuff namely basic (cationic) dyes for acrylic yarns and disperse dyes for polyester yarns in conventional two bath method. Disperse dyes give excellent overall fastness properties with polyester whereas basic dyes are water soluble cationic dyes where the coloured part has a positive charge, interacts with the negative group (either carboxyl or sulfonic acid group) of the fibre molecule (Choi et al., 2000).

In general, the higher temperatures (up to $120{ }^{\circ} \mathrm{C}$ ) are required for dyeing of polyester. The chemical carriers are added at times because boiling water cannot perform the complete job in the presence of disperse dyes above boiling points. These carriers are small aromatic compounds used in dyeing for disperse dyes-bath in solution form to facilitate the dyeing process. The carriers help with the swelling of polyester fibres and increase the inter fibre space and let the dye molecules to penetrate in the hydrophobic fibre system easily, (Iskender et al., 2005).

A survey of the literature showed that polyester/acrylic blends are usually piece layered. Polyester-acrylic fabrics are dyed by a two bath method for improving 
fastness. The polyester should be dyed slight heavily to allow partial transfer of disperse dyes to acrylic during second stage of basic colour dyeing (Choudhury, 2006). Dyeing of acrylic with basic dye was also studied and concluded that it gives very good fastness properties at low temperature and time (Bajaj and Munukutla, 1990).

Dyeing characterisations of alkoxide pre-treated polyester/acrylic fibres blend by the use of a cationic dye in one bath by two steps is also studied by El-Gabry and Bendak (2006). The colour strength of the dyeing generally increased with increasing application temperatures (Sona et al., 2004). Thermodynamic factor and the structural factor of dyeing of acrylic fibre with basic dyes were reported by Wang (2009).

The aim of this study is to characterise the factors that influence the fabric shrinkage with temperature gradient. Also the effect of temperature on fastness properties of dyed acrylic, polyester and polyester/acrylic blended fabrics. The novelty of this work is to define the structural change of acrylic fabric with the increase in temperature, especially when polyester/acrylic blended fabrics are manufactured.

\section{Materials and Methods}

Sample of plain weave pure acrylic fabric with average weight $200 \mathrm{~g} / \mathrm{m}^{2}$ and polyester fabric with average weight $190 \mathrm{~g} / \mathrm{m}^{2}$ were obtained from the Department of Fibre and Textile Technology, University of Agriculture, Faisalabad, Pakistan. Polyester/acrylic fabric was self-manufactured on hand loom. The polyester yarn was used in warp while acrylic yarn was interlaced as weft in order to evaluate the effectiveness of different variables on its dyeing behaviour. The fabrics were pretreated and dyed, later the colour fastness and fabric shrinkage properties of the fabric were evaluated. The plain woven fabric of acrylic, polyester and polyester/acrylic fabric were used with 150 ends/inch and 120 picks/inch.

Pretreatments of acrylic and polyester fabric were carried out in a pan with 1:50 liquor ratio at laboratory scale. Bath was prepared by adding fabric with Sandoclean PC (Detergent) at pH 4 (maintained through addition of acetic acid) and temperature was raised to $70{ }^{\circ} \mathrm{C}$ for $1 \mathrm{~h}$. Firstly, 100\% acrylic fabric was dyed followed by the $100 \%$ polyester and then polyester/acrylic blended fabric. HT (high temperature) dyeing machine was used at laboratory scale. Three fabric samples $\left(\mathrm{F}_{1}=\right.$ Acrylic, $\mathrm{F}_{2}=$ Polyester and $\mathrm{F}_{3}=$ Acrylic/Polyester) were undertaken to design the experiment at four various temperatures $\left(\mathrm{T} 1=100{ }^{\circ} \mathrm{C}, \mathrm{T} 2=110^{\circ} \mathrm{C}, \mathrm{T} 3=120^{\circ} \mathrm{C}, \mathrm{T} 4=130^{\circ} \mathrm{C}\right)$. HT dyeing machine works up to $150{ }^{\circ} \mathrm{C}$ with the capacity of $300 \mathrm{~mL}$. 10 dyeing pots are fixed homogeneously in oil heating system controlled by the intelligent controller T- 410 NB HT:

Acrylic fabric with 1:50 liquor ratio was added to steel glasses based dyebaths. The amount of $1 \mathrm{~g}$ of cationic red-3R basic dye (Hangzhou Emperor Chemical Co., Ltd.) was added with $99 \mathrm{~mL}$ of boiling water. After well shaking, it was diluted to $100 \mathrm{~mL}$ to get $1 \%$ stock solution. Stock solution of basic dye was added to dyebath with $2 \%$ sodium acetate. Temperature (100, 110,120 and $130^{\circ} \mathrm{C}$ ) was varied in each test with fixed $\mathrm{pH}(6)$ and time (30 min). Dyebath glasses were closed with sealed caps and adjusted in the revolving portion (revolving speed $30 \mathrm{rpm}$ ) of HT dyeing machine (Yaman et al., 2009). All the processes were automatically controlled. After completing $25 \mathrm{~min}$, automatic cooling started and temperature was reduced to $50{ }^{\circ} \mathrm{C}$. The dyebaths were opened; samples were taken out, washed, rinsed, cooled and dried. For each test, time and temperature was adjusted after setting $\mathrm{pH}$ level inside the dyebath. Every fabric has an optimum limit of $\mathrm{pH}$ value for dyeing. The variation in $\mathrm{pH}$ results in the fibre degradation or wastage of dye.

Polyester fabric with 1:50 liquor ratio was used in dyebath steel glasses. The amount of $1 \mathrm{~g}$ of Red-FB disperse dye (Hangzhou Emperor Chemical Co., Ltd.) was included with $99 \mathrm{~mL}$ of boiling water. By shaking, it was diluted to $100 \mathrm{~mL}$ to get $1 \%$ stock solution. A stock solution of disperse dye was put into dyebath. As similar to acrylic fabric dyeing, temperature (100, 110, 120 and $130{ }^{\circ} \mathrm{C}$ ) was varied by fixing the $\mathrm{pH}(6)$ and time $(40 \mathrm{~min})$ in each test. For the dyeing of polyester/acrylic fabric one bath two stage method was used. The dyeing of blends containing acrylic was considered first because of the circulation of dye liquor through a mass of fibre and then polyester dyeing by the blend components.

Same as above method was used for dyeing with two different recipes separately. But before second stage the samples were passed from cold wash process with $\mathrm{HCl}(1 \mathrm{~g} / \mathrm{L})$ to neutralize. 
After all possible treatment combinations of dyeing methods, with variables and constants, the fabric samples were subjected to colour fastness and shrinkage tests. The dyed fabric samples were tested for washing (ISO 105-C04), rubbing (dry and wet) (ISO 105-X12), perspiration (acidic and alkaline) (ISO 105-E04), ironing (dry and wet) (ISO 105-X11), light fastness (ISO 105B02) properties and shrinkage. AATCC (2003) standard was used for colour fastness properties. The data thus obtained from the shrinkage test were analysed statistically as suggested by Faqir (2004), using M-Stat micro computer statistical program devised by Freed (1992).

\section{Results and Discussion}

The aim of the present research is to study the effect of dyeing temperature by fixing the dyeing time and $\mathrm{pH}$ of dyebath on acrylic fabric, polyester fabric and its $\mathrm{P} / \mathrm{A}$ blended fabric.

Fastness properties. The grey scale rating for all the samples responded from very good (4) to excellent (5) for all fabric samples $\left(F_{1}=\right.$ acrylic, $F_{2}=$ polyester, and $\mathrm{F}_{3}=$ =olyester/acrylic). Temperature affected the washing fastness significantly at $\mathrm{T}_{3}\left(120^{\circ} \mathrm{C}\right)$ and $\mathrm{T}_{4}\left(130{ }^{\circ} \mathrm{C}\right)$, while at $\mathrm{T}_{1}\left(100{ }^{\circ} \mathrm{C}\right)$ and $\mathrm{T}_{2}\left(110^{\circ} \mathrm{C}\right)$ acrylic fabric countered very good (4) grading as stated by De Giorgi et al. (2000) and shown in Fig. 1.

Light fastness, the blue scale rating appeared very good (6) to excellent (7) for all fabric specimens as reported by Dr. Giorge et al. (2000) but at temperature $\mathrm{T}_{3}$ and $\mathrm{T}_{4}$ light fastness improved slightly as shown in Fig. 2.

The rubbing fastness (dry) for all the samples reciprocated from very good (4) to excellent (5) range while only very good (4) values were noted in wet form at $\mathrm{T}_{1}, \mathrm{~T}_{2}$ and $\mathrm{T}_{3}$ but slightly improved at $\mathrm{T}_{4}$ (Yi et al. $2005)$. With the increase in dyeing temperature the rubbing fastness (dry and wet) was also upgraded as given in Fig. 3.

Likewise the rubbing fastness (dry), ironing fastness (dry) countered from very good (4) to excellent (5) at grey scale while only very good (4) value were noted in wet form at $\mathrm{T}_{1}, \mathrm{~T}_{2}$ and $\mathrm{T}_{3}$ but moderately improved at $\mathrm{T}_{4}$ (Mahltig et al., 2004). As the dyeing temperature raised, the ironing fastness (dry and wet) was also refined as shown in Fig. 4.

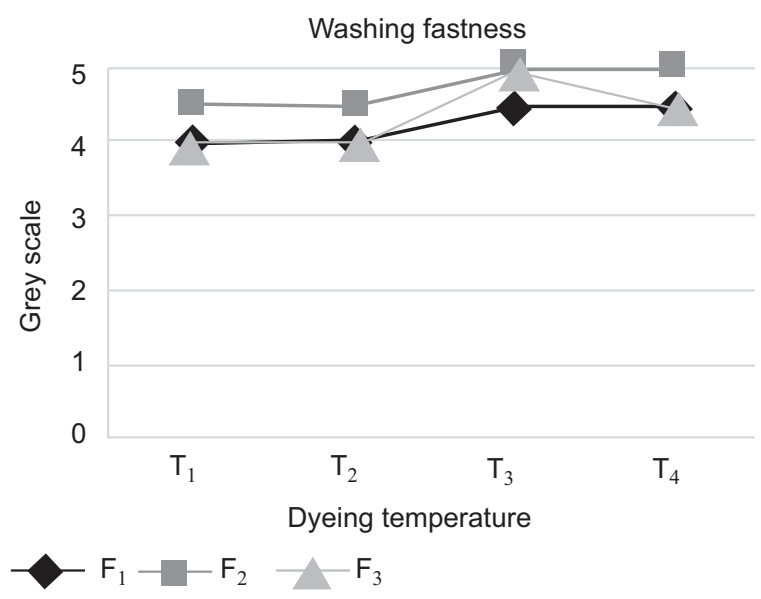

Fig. 1. Effect of dyeing temperature $\left(\mathrm{T}_{1}=100{ }^{\circ} \mathrm{C}\right.$, $\mathrm{T}_{2}=110^{\circ} \mathrm{C}, \mathrm{T} 3=120^{\circ} \mathrm{C}, \mathrm{T} 4=130{ }^{\circ} \mathrm{C}$ ) on the washing fastness of dyed acrylic $\left(\mathrm{F}_{1}\right)$, polyester $\left(\mathrm{F}_{2}\right)$ and polyester/acrylic $\left(\mathrm{F}_{1}\right)$ blended fabric. Grey scale rating: Excellent $=5$, Very $\operatorname{good}=4$, good $=3$, Moderate $=2$, Poor $=1$.

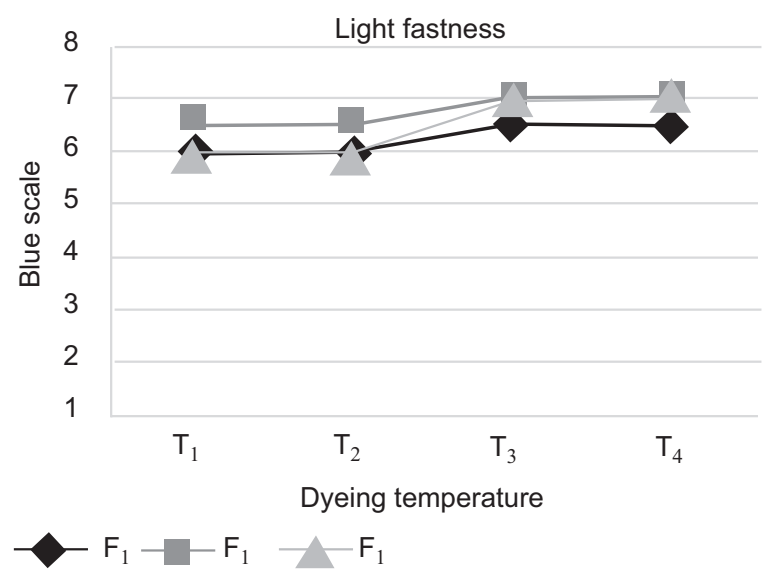

Fig. 2. Effect of dyeing temperature $\left(\mathrm{T}_{1}=100{ }^{\circ} \mathrm{C}\right.$, $\mathrm{T}_{2}=110^{\circ} \mathrm{C}, \mathrm{T}_{3}=120^{\circ} \mathrm{C}, \mathrm{T}_{4}=130^{\circ} \mathrm{C}$ ) on the light fastness of dyed acrylic $\left(\mathrm{F}_{1}\right)$, polyester $\left(\mathrm{F}_{2}\right)$ and polyester/acrylic $\left(\mathrm{F}_{3}\right)$ blended fabric. Blue wool grading: Outstanding $=8$, Excellent $=7$, Very good $=6$, good $=5$, Very Fair $=4$, Fair $=3$, Poor $=2$, Very Poor $=1$.

The grey scale rating in Fig. 5 was very good (4) to excellent (5) for the perspiration fastness (acidic), although it was excellent (5) at $\mathrm{T}_{3}$ and $\mathrm{T}_{4}$ for the polyester fabric. 


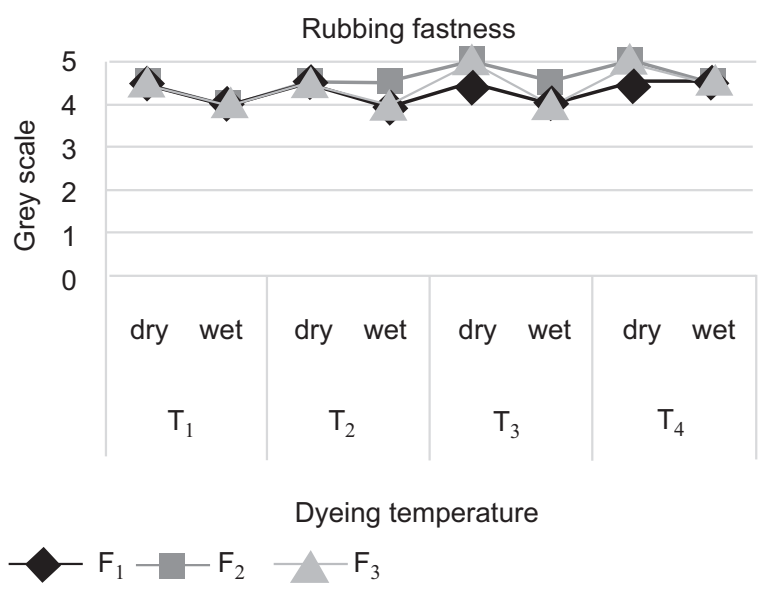

Fig. 3. Effect of dyeing temperature $\left(\mathrm{T}_{1}=100{ }^{\circ} \mathrm{C}\right.$, $\mathrm{T}_{2}=110{ }^{\circ} \mathrm{C}, \mathrm{T}_{3}=120^{\circ} \mathrm{C}, \mathrm{T}_{4}=130^{\circ} \mathrm{C}$ ) on the rubbing fastness (dry and wet) of dyed acrylic $\left(\mathrm{F}_{1}\right)$, polyester $\left(\mathrm{F}_{2}\right)$ and polyester/acrylic $\left(\mathrm{F}_{3}\right)$ blended fabric. Grey scale rating: Excellent $=5$, Very good $=4$, Good $=3$, Moderate $=2$, Poor $=1$.

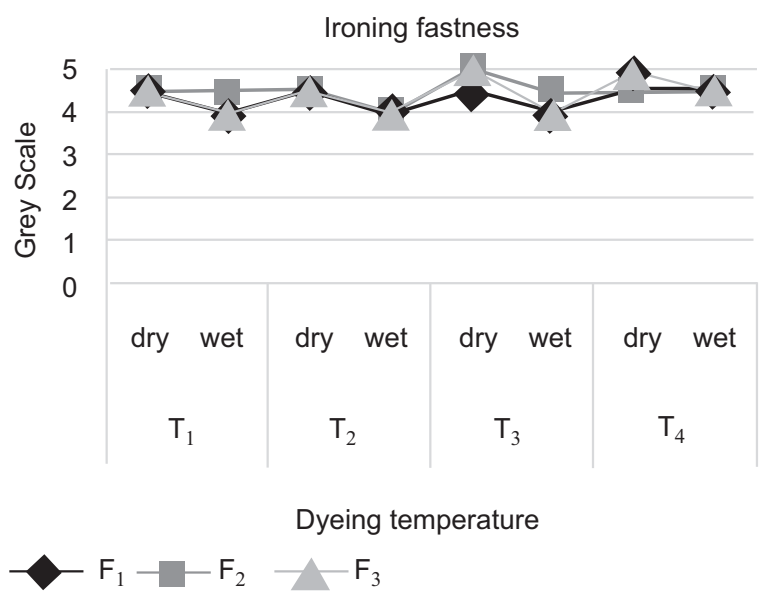

Fig. 4. Effect of dyeing temperature $\left(\mathrm{T}_{1}=100{ }^{\circ} \mathrm{C}\right.$, $\mathrm{T}_{2}=110{ }^{\circ} \mathrm{C}, \mathrm{T}_{3}=120^{\circ} \mathrm{C}, \mathrm{T}_{4}=130^{\circ} \mathrm{C}$ ) on the ironing fastness (dry and wet) of dyed acrylic $\left(\mathrm{F}_{1}\right)$, polyester $\left(\mathrm{F}_{2}\right)$ and polyester/ acrylic $\left(\mathrm{F}_{3}\right)$ blended fabric. Grey scale rating: Excellent $=5$, Very Good $=4$, good $=3$, Moderate $=2$, Poor $=1$.

Graphical representation of shrinkage explained the direction proportion of acrylic fabric to dyeing temperature.

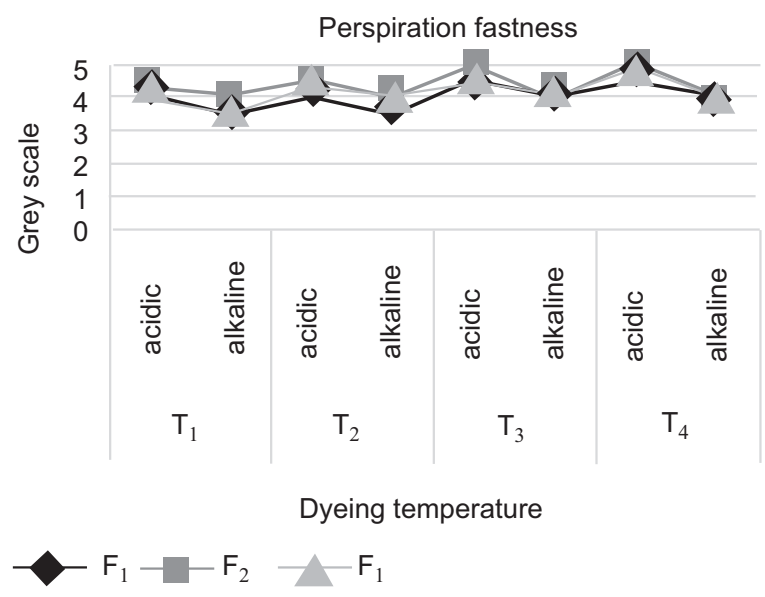

Fig. 5. Effect of dyeing temperature $\left(\mathrm{T}_{1}=100{ }^{\circ} \mathrm{C}\right.$, $\mathrm{T}_{2}=110{ }^{\circ} \mathrm{C}, \mathrm{T}_{3}=120^{\circ} \mathrm{C}, \mathrm{T}_{4}=130{ }^{\circ} \mathrm{C}$ ) on the perspiration fastness (acidic and alkaline) of dyed acrylic $\left(\mathrm{F}_{1}\right)$, polyester $\left(\mathrm{F}_{2}\right)$ and polyester/acrylic $\left(\mathrm{F}_{3}\right)$ blended fabric. Grey scale rating: Excellent $=5$, Very good $=4$, Good $=3$, Moderate $=2$, Poor $=1$.

With the increase in dyeing temperature the shrinkage percentage also increased as given in Fig. 6. However, polyester fabric endured the temperature gradient, (Velazquez et al., 2000). The statistical comparison of individual treatment means for fabric shrinkage is presented in Table 1. In warp wise shrinkage, the individual comparison of mean values of fabric samples showed non-significant difference between the mean values of shrinkage obtained for polyester and polyester/acrylic but these values had significant difference from acrylic fabric. Similarly, temperature exhibited higher shrinkage with the increase of temperature gradient (Dyurnbaum and Bogdanov 1971). The comparison of all temperatures was observed significant, while last three temperatures appeared non-significant against each other (Sardag et al., 2007).

Fabric shrinkage (weft wise) analysis of variance revealed high significant effect of fabric samples between the mean values as shown in Table 1 . Comparison of mean values between $T_{1}$ and $T_{2}$ was highly significant while non-significant for $T_{2}, T_{3}$ and $\mathrm{T}_{4}$. 


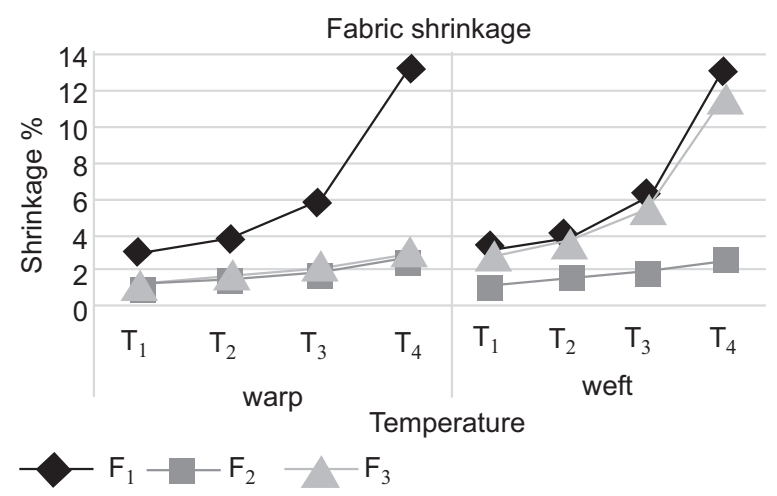

Fig. 6. Effect of dyeing temperature $\left(\mathrm{T}_{1}=100{ }^{\circ} \mathrm{C}\right.$, $\mathrm{T}_{2}=110{ }^{\circ} \mathrm{C}, \mathrm{T}_{3}=120^{\circ} \mathrm{C}, \mathrm{T}_{4}=130^{\circ} \mathrm{C}$ ) on the shrinkage (warp and weft) of dyed acrylic (F1), polyester (F2) and acrylic/polyester (F3) blended fabric.

Table 1. Comparison of individual treatment means of fabric shrinkage

\begin{tabular}{lllll}
\hline \hline \multicolumn{2}{c}{ Warp wise } & & \multicolumn{2}{c}{ Weft wise } \\
\cline { 1 - 2 } \cline { 5 - 6 } $\begin{array}{llll}\text { Fabric sample } \\
\text { (F) }\end{array}$ & Temperature & & Fabric sample & Temperature \\
& $(\mathrm{T})$ & & $(\mathrm{F})$ & $(\mathrm{T})$ \\
\hline $\mathrm{AC}=6.462 \mathrm{~A}$ & $\mathrm{~T}_{1}=2.219 \mathrm{~B}$ & & $\mathrm{AC}=6.497 \mathrm{~A}$ & $\mathrm{~T}_{1}=2.944 \mathrm{~B}$ \\
$\mathrm{PE}=1.772 \mathrm{~B}$ & $\mathrm{~T}_{2}=6.088 \mathrm{~A}$ & & $\mathrm{PE}=1.785 \mathrm{C}$ & $\mathrm{T}_{2}=7.591 \mathrm{~A}$ \\
$\mathrm{AC} / \mathrm{PE}=1.770 \mathrm{~B}$ & $\mathrm{~T}_{3}=6.088 \mathrm{~A}$ & & $\mathrm{AC} / \mathrm{PE}=4.585 \mathrm{~B}$ & $\mathrm{~T}_{3}=7.591 \mathrm{~A}$ \\
& $\mathrm{~T}_{4}=6.088 \mathrm{~A}$ & & $\mathrm{~T}_{4}=7.591 \mathrm{~A}$ \\
\hline \hline
\end{tabular}

\section{Conclusion}

The study revealed that after well pretreatments, for maximum dye utilization, dyeing process was carried out under the optimal level of controlling parameters. The rise in temperature from $120^{\circ} \mathrm{C}$ to $130^{\circ} \mathrm{C}$ caused an increase in the shrinkage of the acrylic yarns. For this reason, dyeing temperature at $120{ }^{\circ} \mathrm{C}$ can be considered sufficient for the acrylic and polyester/ acrylic fabric. However, high shrinkage was ultimate at $130{ }^{\circ} \mathrm{C}$ for acrylic fabric. Aggregately, colour fastness practiced good to excellent results. It was observed that dyeing of acrylic fabric in acidic medium with basic dyes is favorable for dye fixation while dyeing of polyester fabric was attained in disperse dyes. The maximum dye utilization and optimum results were observed at $\mathrm{pH} 6$ for $30 \mathrm{~min}$ dyeing time in dyebath.

\section{Acknowledgement}

The auther greatly appreciate the cooperation of Naeem Ahmad Awan, Ex-lab head of Hilal Textile Pvt. Ltd. FSD, Pakistan.

\section{References}

Bajaj, P., Munukutla, S.K. 1990. Effect of spinning dope additives on dyeing behaviour of acrylic fibres. Textile Research Journal, 60: 113-118.

Choi, J.H., Lee, S.H., Towns, E.J. A.D. 2000. Structurewet fastness relationships of some blue disperse dyes for polyester. Coloration Technology, 116: 273-278.

Choudhury, A.K. 2006. Textile Preparation and Dyeing, Science Publishers, illustrated Edition New Hampshire, USA.

Dyurnbaum, V.S., Bogdanov, M.N. 1971. Highshrinkage fibres based on the co-polyesters of dimethyl terephthalate and dimethyl-5-hydroxyisophthalate. Fibres Chemistry, 2: 88-88.

De Giorgi, M.R., Cadoni, E., Maricca, D., Piras, A. 2000. Dyeing polyester fibres with disperse dyes in supercritical $\mathrm{CO}_{2}$. Dyes and Pigments, 45: 75-79.

El-Gabry, L.K., Bendak, A. 2006. Dyeing characterizations of alkoxide pre-treated acrylic-polyester fibres blend by the use of a cationic dye. Polish Journal of Applied Chemistry, 3: 83-94.

Freed, R. 1992. M-Stat Micro Computer Statistical Program, Plant and Soil Sciences, Michigan State University. East Lansing, Michigan, USA.

Iskender, M.A., Becerir, B., Koruyucu, A. 2005. Carrier dyeing of different energy level disperse dyes on polyester fabric. Textile Research Journal, 75: 462-465.

Mahltig, B., Böttcher, H., Knittel, D., Schollmeyer, E. 2004. Light fading and wash fastness of dyed nanosol-coated textiles. Textile Research Journal, 74: 521-527.

Sardag, S., Ozdemir, O., Kara, I. 2007. The effects of heat-setting on the properties of polyester/viscose blended yarns. FIBRES \& TEXTILES in Eastern Europe, 63: 50-53.

Siddique, S. 1999. Spectrophotometric Studies on the Dyeing of Acrylic and Viscose Fabrics. M.Sc. Thesis, pp. 194, University of Agriculture, Faisalabad, Pakistan. 
Siddiqui, S.A., Needles, H.L. 1982. Studies of solvent dyeing part II: Solvent dyeing behavior of new disperse dyes on polyethylene terephthalate fiber. Textile Research Journal, 52: 403-411.

Sona, Y.A., Hong, J.P., Kim, T.K. 2004. An approach to the dyeing of polyester fibre using indigo and its extended wash fastness properties. Dyes and Pigments, 61: 263-272.

Ujhelyiova, A., Bolhova, E., Oravkinova, J., Tino, R., Marcincin, A. 2007. Kinetics of dyeing process of blend polypropylene/polyester fibres with disperse dye. 72: 212-216.

Velazquez, R., Sanchez, F., Yanez, R., Castano, V.M. 2000. Synthesis of shrinkage-controlled acrylic copolymers. Journal of Applied Polymer Science, 78: 586-591.

Wang, H.H. 2009. Accessibility of acrylic fibre to basic dye. Journal of Applied Polymer Science, 111: 189-193.

Yaman, N., Özdoðan, E., Seventekin, N., Ayhanc, H. 2009. Plasma treatment of polypropylene fabric for improved dyeability with soluble textile dyestuff. Applied Surface Science, 255: 67646770 .

Yi, Z., Jihong, H., Shuilin, C. 2005. Dyeing of polyester using micro-encapsulated disperse dyes in the absence of auxiliaries. Colouration Technology, 121: $76-80$. 